\title{
Vortex-Induced Vibration Suppression of a Circular Cylinder with Vortex Generators
}

\author{
Shi-bo Tao,, ${ }^{1,2}$ Ai-ping Tang,, ${ }^{1,2}$ Da-bo Xin,, ${ }^{1,2}$ Ke-tong Liu, ${ }^{3}$ and Hong-fu Zhang ${ }^{1,2}$ \\ ${ }^{1}$ Key Lab of Structures Dynamic Behavior and Control, Harbin Institute of Technology, Ministry of Education, Heilongjiang, \\ Harbin 150090, China \\ ${ }^{2}$ School of Civil Engineering, Harbin Institute of Technology, Harbin 150090, China \\ ${ }^{3}$ College of Architecture and Civil Engineering, Xian University of Science and Technology, Xi'an 710054, China
}

Correspondence should be addressed to Ai-ping Tang; 972870139@qq.com

Received 30 November 2015; Revised 24 May 2016; Accepted 9 June 2016

Academic Editor: Carlo Trigona

Copyright (C) 2016 Shi-bo Tao et al. This is an open access article distributed under the Creative Commons Attribution License, which permits unrestricted use, distribution, and reproduction in any medium, provided the original work is properly cited.

\begin{abstract}
The vortex-induced vibration is one of the most important factors to make the engineering failure in wind engineering. This paper focuses on the suppression method of vortex-induced vibration that occurs on a circular cylinder fitted with vortex generators, based on the wind tunnel experiment. The effect of the vortex generators is presented with comparisons including the bare cylinder. The experimental results reveal that the vortex generators can efficiently suppress vortex-induced vibration of the circular cylinder. Vortex generator control can make the boundary layer profile fuller and hence more resistant to separation. The selections of skew angles and the angular position have a significant influence on the vortex generator control effect. By correlation analysis, it can be concluded that the vortex generators can inhibit the communication between the two shear layers and produce streamwise vortices to generate a disturbance in the spanwise direction.
\end{abstract}

\section{Introduction}

The stay-cables and hangers are the key components of longspan bridges. They are prone to vortex-induced vibration (VIV) due to their high flexibility and low damping ratio. Although the VIV is self-limiting, it may induce violent structural vibrations and stresses that eventually lead to considerable fatigue damage and reduction in the structural lifetime of stay-cables and hangers [1]. Therefore, strategies aiming at reducing vibration amplitudes for stay-cables and hangers are of great concern for industry and academia $[2,3]$. Most of the algorithms of fatigue analysis of stay-cables and hangers subjected to VIV consider that the flow around an inclined circular cylinder can be considered equivalent to the one in which the free stream velocity is projected onto the direction orthogonal to the circular cylinder axis [4]. In the present work, we referred this simplification.

Flow control involves active and passive devices [5]. Active devices require energy expenditure. Kim and Choi [6] studied a forcing scheme for cylinder drag reduction by blowing and suction of fluid through two slits located on the surface of the cylinder. Muralidharan et al. [7] designed a suction control strategy for a circular cylinder and implemented it to assess its efficacy. Bigger et al. [8] applied openloop control in the near wake of a disk in subsonic air and water flows. Passive devices require no auxiliary power and no control loop $[9,10]$. Adachi [11] considered the influence of different surface roughness values for a circular cylinder wake. Chen et al. [12] investigated passive jet flow control technique to manipulate the vortex shedding process from a circular cylinder. Oruç [13] studied flow control around a circular cylinder with a screen that had a streamlined shape. Bao and Tao [14] used dual plates to control the wake of a circular cylinder.

Vortex generators (VGs) are effective at controlling boundary layer. This control method can stimulate vertical motions confined in the boundary layer and its close surroundings, hence, providing momentum enhancement in the vicinity of a wall [15]. The simple geometrical properties of passive VGs can provide relatively practical and low cost effective solutions to complex flow separation phenomena. Therefore, VGs are commonly used as flow control devices, 
especially in aerodynamic applications. Many results of using VGs to control stationary cylinders were available at present. Ünal and Atlar [16] used VGs to control the wake flow of a cylinder. Their study shows that vortex generators enforced the shear layers to bend towards the centreline and decrease the width of the wake. Shur et al. [17] show that VGs can produce a significant delay of separation and drag reduction in flows past smooth bluff bodies in the transcritical flow regime, with turbulent boundary layers ahead of separation.

In the present investigation, a vortex generator control method was adopted to mitigate the VIV of a circular cylinder. The Reynolds numbers in the present work were in the range of $10^{4} \sim 10^{5}$, which is within the subcritical regime.

\section{Vortex Generator Design}

Based on the literature survey review, the triangular VGs are adopted in this paper. This is a thin plastic plate vortex generator with a $0.2 \mathrm{~mm}$ thickness as suggested by Godard and Stanislas [18]. Figure 1 shows the geometrical parameters. $L$ is the distance between the trailing edges of two triangular plates of one pair; $h$ is the height of the triangular plates; $l$ is the length of the triangular plates; $\lambda$ is the distance between two passive devices; and $\beta$ is the skew angle. Before the experiment, we conducted computational simulations to determine the boundary layer thickness $(\delta)$ of the circular cylinder. The boundary layer thickness was approximately $1.5 \mathrm{~mm}-1.9 \mathrm{~mm}$ near the separation line $(\mathrm{Re}=10000)$. The height of the VGs can be greater than that of the boundary layer thickness. Therefore, the VGs used in this experiment were $\delta$-scale, with $h / \delta \sim 2$. In the experiment, the heights of the VGs were set at $h=4 \mathrm{~mm}$. The sizes of the VGs were determined according to the suggestion given in [18]. In this way, $l / h=1.5, \lambda / h=4$, and $L / h=1.5$. Configurations of the VGs are shown in Figure 2, where $U$ is the free stream, and the positive and negative skew angle are shown in Figures 2(a) and 2(b).

\section{Experimental Setup}

3.1. Experimental Facility. This experiment was performed in the wind tunnel at the Harbin Institute of Technology (HIT) in China. The wind tunnel is a closed-circuit tunnel with a rectangular test section that is $4 \mathrm{~m}$ wide, $3 \mathrm{~m}$ high, and $25 \mathrm{~m}$ long. The wind speed $(U)$ is continuously variable and the flow has a longitudinal turbulence intensity of less than $0.46 \%$.

3.2. Cylinder Model. The cylinder model used in these experiments was made of an acrylic resin pipe with a length $\left(L_{c}\right)$ of $1.2 \mathrm{~m}$, a diameter of $0.3 \mathrm{~m}$, and a wall thickness of $6 \mathrm{~mm}$. The model was approximately $12 \mathrm{~kg}$. This cylinder was instrumented with 120 surface pressure taps arranged in four rows along the span of the cylinder, as shown in Figure 3(a). Each row contained 30 pressure taps distributed azimuthally about the circumference of the cylinder. They were distributed at an equal spacing $\left(\Delta \alpha=12^{\circ}\right)$, as shown in Figure 3(b). The $x$-coordinate is along the oncoming flow

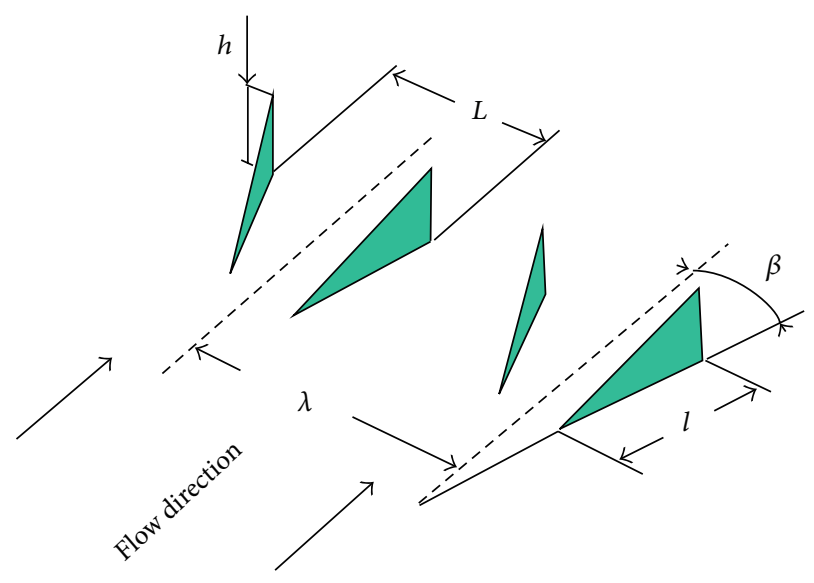

FIGURE 1: Vortex generator geometry [18].

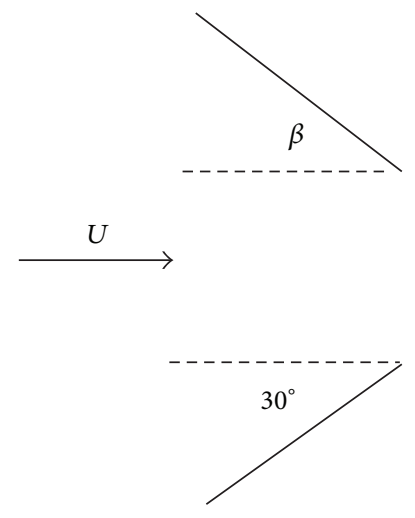

(a) $\beta=30^{\circ}$
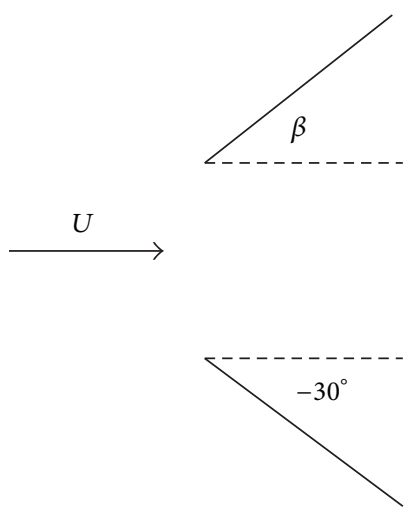

(b) $\beta=-30^{\circ}$
FIgURE 2: Vortex generator configuration (top view).

direction, and the $y$-coordinate is perpendicular to the flow direction.

The cylinder was hung on a free vibration device (Figure 4). Two end-plates were used to foster a bidimensional flow [19]. The stiffness of the coil spring was $860 \mathrm{~N} / \mathrm{m}$. The coil springs were attached symmetrically on the lever arms with a lateral spacing of $450 \mathrm{~mm}$. The vertical damping ratio was $2 \%$ and the natural vertical frequency $\left(f_{n}\right)$ was $3.8 \mathrm{~Hz}$. The blockage ratio of the experiment facility was $4.5 \%$, and it was unnecessary to correct the data for the blockage effect according to [20].

In Figure 5(a), the vortex generators were longitudinally fitted on a circular cylinder. In Figure 5(b), the angular position $\left(0^{\circ}<\theta<180^{\circ}\right)$ of the row was from the front stagnation line.

Two Type 4507B accelerometers were fixed on both ends of the circular cylinder. The acceleration measurements were obtained at a sampling frequency of $1000 \mathrm{~Hz}$ for a period of 20 s. The DSM 3400 system (Scanivalve Corporation) was used to measure the pressure. The sampling rate was $300 \mathrm{~Hz}$. The sampling duration was $40 \mathrm{~s}$. 


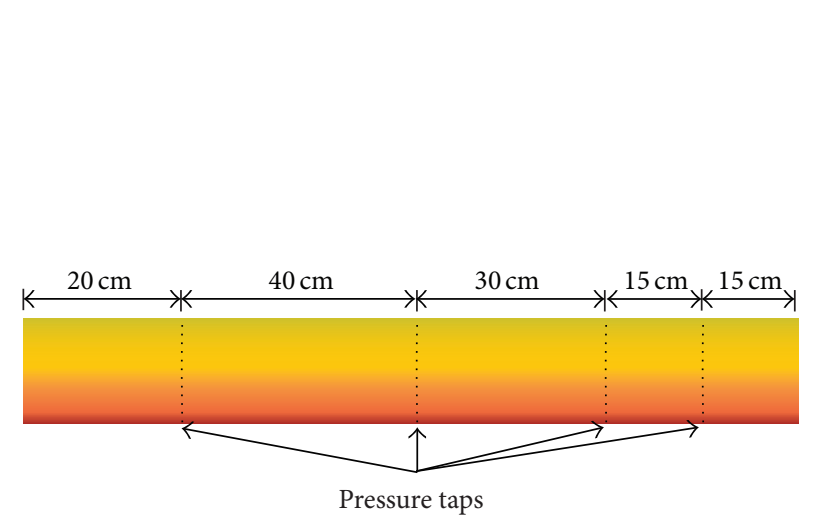

(a) Surface pressure taps

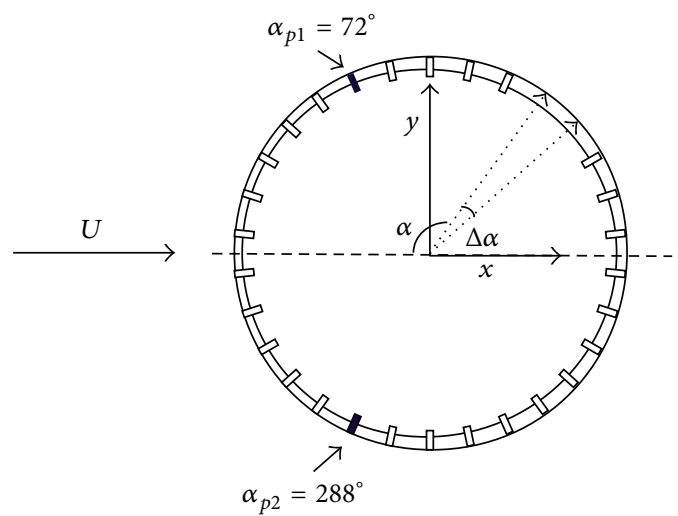

(b) Arrangement of the pressure taps

FIgURE 3: Pressure tap arrangements.

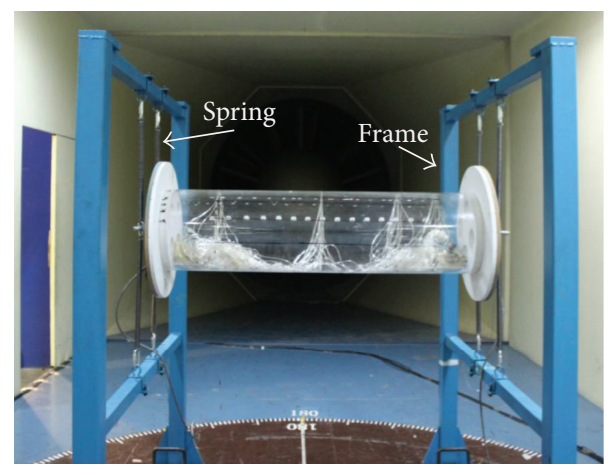

FIGURE 4: Experiment facility.

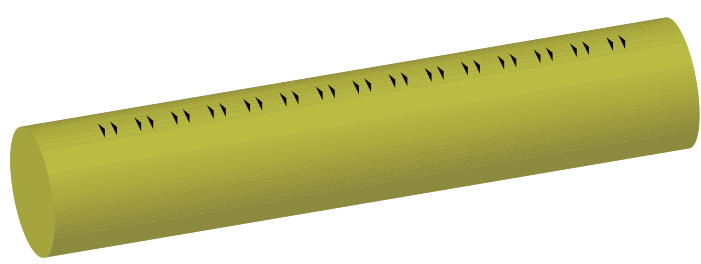

(a) The circular cylinder with VGs

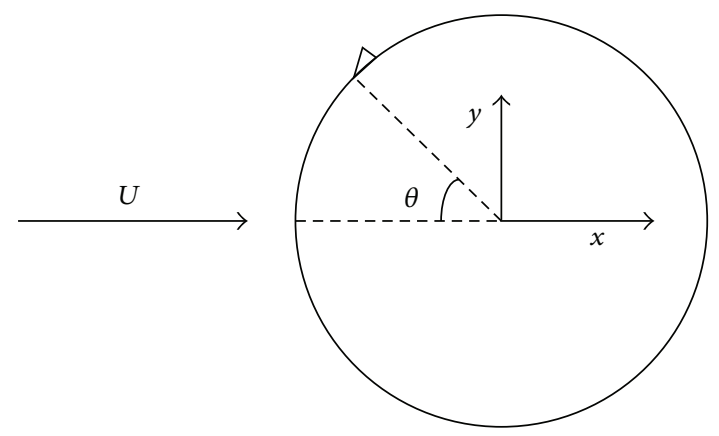

(b) Side view of the circular cylinder with VGs

FIgURE 5: The angular position.

The aerodynamic coefficients were obtained by integrating the wind pressures over all of the taps; the drag and lift coefficients, $C_{x}$ and $C_{y}$, were then calculated with the following expression:

$$
\begin{aligned}
C_{p_{i}} & =\frac{p_{i}-p_{\infty}}{1 / 2 \cdot \rho U_{0}^{2}}, \\
C_{p i}^{\prime} & =\frac{p_{i, \mathrm{rms}}}{1 / 2 \cdot \rho U_{0}^{2}},
\end{aligned}
$$

$$
\begin{aligned}
C_{x} & =\frac{F_{x}}{1 / 2 \rho U_{0}^{2} D} \\
& =\frac{1 / 2 \cdot \rho U_{0}^{2} \sum_{i} C_{p i} \cdot 1 / 2 \cdot D \Delta \theta_{i} \cdot \cos \theta_{i}}{1 / 2 \cdot \rho U_{0}^{2} D} \\
& =\frac{1}{2} \sum_{i} C_{p i} \Delta \theta_{i} \cos \theta_{i}, \\
C_{y} & =\frac{F_{y}}{1 / 2 \rho U_{0}^{2} D}
\end{aligned}
$$




$$
\begin{aligned}
& =\frac{1 / 2 \cdot \rho U_{0}^{2} \sum_{i} C_{p i} \cdot 1 / 2 \cdot D \Delta \theta_{i} \cdot \cos \theta_{i}}{1 / 2 \cdot \rho U_{0}^{2} D} \\
& =\frac{1}{2} \sum_{i} C_{p i} \Delta \theta_{i} \sin \theta_{i},
\end{aligned}
$$

where $C_{p_{i}}$ is the pressure coefficient, $p_{i}$ is the pressure on the model, $p_{\infty}$ is the static pressure of the free stream, $\rho$ is the air density, $\rho=1.225 \mathrm{~kg} / \mathrm{m}^{3}, C^{\prime}{ }_{p}$ is the pressure fluctuation, $p_{i, \mathrm{rms}}$ is the root-mean-square of the pressure fluctuations, and $F_{x}$ and $F_{y}$ are the aerodynamic drag and lift forces acting on the cylinder model in the $x$ - and $y$-directions, respectively. Equations (1a), (1b), (1c), and (1d) were used for the spanwise correlation coefficients of the lift force.

3.3. Measurement Uncertainty. The uncertainty of the Re number can be written as [21]

$$
\begin{aligned}
u_{\operatorname{Re}}^{2}= & \left(\frac{U}{\operatorname{Re}} \frac{\partial \operatorname{Re}}{\partial U} u_{U}\right)^{2}+\left(\frac{v}{\operatorname{Re}} \frac{\partial \operatorname{Re}}{\partial \nu} u_{v}\right)^{2} \\
& +\left(\frac{H}{\operatorname{Re}} \frac{\partial \operatorname{Re}}{\partial D} u_{d}\right)^{2},
\end{aligned}
$$

where $v$ is the kinematic viscosity, $\mathrm{m}^{2} / \mathrm{s}$, and $u$ is the uncertainty. Using the values of the partial derivatives,

$$
\begin{aligned}
& \frac{\partial \operatorname{Re}}{\partial U}=\frac{D}{v} ; \\
& \frac{\partial \operatorname{Re}}{\partial D}=\frac{U}{D} ; \\
& \frac{\partial \operatorname{Re}}{\partial \nu}=(-1) \frac{U D}{v^{2}} .
\end{aligned}
$$

Equation (2) can be rewritten as

$$
\begin{aligned}
u_{\mathrm{Re}}^{2}= & \left(\frac{U}{U H / \nu} \frac{H}{v} u_{U}\right)^{2}+\left(\frac{U}{U H / \nu} \frac{U}{v} u_{H}\right)^{2} \\
& +\left(\frac{U}{U H / \nu}(-1) \frac{U H}{v^{2}} u_{\nu}\right)^{2} \Longrightarrow \\
u_{\mathrm{Re}}^{2}= & \left(u_{U}\right)^{2}+\left(u_{H}\right)^{2}+\left(u_{\nu}\right)^{2} .
\end{aligned}
$$

The uncertainty of the free stream velocity $u_{U}$ was $1.5 \%$. The uncertainty of the diameter of the circular cylinder model $u_{H}$ was $7 \%$ o. The uncertainty of the kinematic viscosity of air was approximately 4\%o. The total uncertainty of the $\mathrm{Re}$ number given by (2) has been determined as $u_{\mathrm{Re}}^{2}=(1.5 \%)^{2}+$ $(7 \% \text { o })^{2}+(4 \% \text { o })^{2}=2.9 \%$.
The surface pressure coefficient uncertainty can be written as

$$
\begin{aligned}
u_{C p} & =\left[\left(\frac{\Delta p}{C_{p}} \frac{\partial C_{p}}{\partial \Delta p} u_{\Delta p}\right)^{2}+\left(\frac{\rho}{C_{p}} \frac{\partial C_{p}}{\partial \Delta p} u_{\rho}\right)^{2}\right. \\
+ & \left.\left(\frac{U}{C_{p}} \frac{\partial C_{p}}{\partial U} u_{U}\right)^{2}\right]^{1 / 2} .
\end{aligned}
$$

The partial derivatives in (5) can be written as

$$
\begin{aligned}
& \frac{\partial C_{p}}{\partial \Delta p}=\frac{2}{\rho U^{2}} ; \\
& \frac{\partial C_{p}}{\partial \rho}=\frac{-2 \Delta p}{\rho^{2} U^{2}} ; \\
& \frac{\partial C_{p}}{\partial U}=\frac{-4 \Delta p}{\rho U^{3}} .
\end{aligned}
$$

The uncertainty of the pressure coefficient is obtained as

$$
\begin{aligned}
u_{C_{p}} & =\left[\left(\frac{\Delta p}{2 \Delta p / \rho U^{2}} \frac{2}{\rho U^{2}}\right)^{2}+\left(\frac{\rho}{2 \Delta p / \rho U^{2}} \frac{-2 \Delta p}{\rho^{2} U^{2}} u_{\rho}\right)^{2}\right. \\
+ & \left.\left(\frac{U}{2 \Delta p / \rho U^{2}} \frac{-2 \Delta p}{\rho U^{3}}\right)^{2}\right]^{1 / 2} \Longrightarrow
\end{aligned}
$$

$u_{C p}^{2}=u_{\Delta p}^{2}+u_{\rho}^{2}+4 u_{U}^{2}$

where $u_{\Delta p}=2.5 \%$ and $u_{\rho}=2 \%$. Finally, $u_{C p}=3.9 \%$.

The uncertainty of the accelerometer was obtained from the calibration chart for the Type 4507B accelerometer. The expanded uncertainly was $1.0 \%$, as determined in accordance with EAL-R2 [22]. A coverage factor of $k=2$ was used.

\section{Experiment Results and Analysis}

In the experiment, the wind speeds ranged from $5 \mathrm{~m} / \mathrm{s}$ to $13 \mathrm{~m} / \mathrm{s}$. The corresponding reduced wind speed $(U r)$ was $U / f_{n} D$. The amplitude of the bare circular cylinder versus the reduced wind speed is produced in Figure 7. The amplitude of the model was calculated by

$$
A=\sqrt{2 \cdot \sigma^{2}}
$$

where $A$ is the amplitude and $\sigma^{2}$ is the variance of the displacement. Equation (8) is likely to give an underestimation of the maximum response but was judged to be perfectly acceptable for assessing the effectiveness of VIV suppression devices. The comparison of the ratio of the vortex shedding frequency and the vertical natural vibration frequency of the circular cylinder is shown in Figure 7 as a function of the reduced wind speed.

In Figure 6, when the reduced wind speed range is 4.410.7, the vibration amplitude of the circular cylinder increases first, peaks at $U r=7$, and then decreases. Also as shown in Figure 7, a lock-in phenomenon is observed in the reduced 


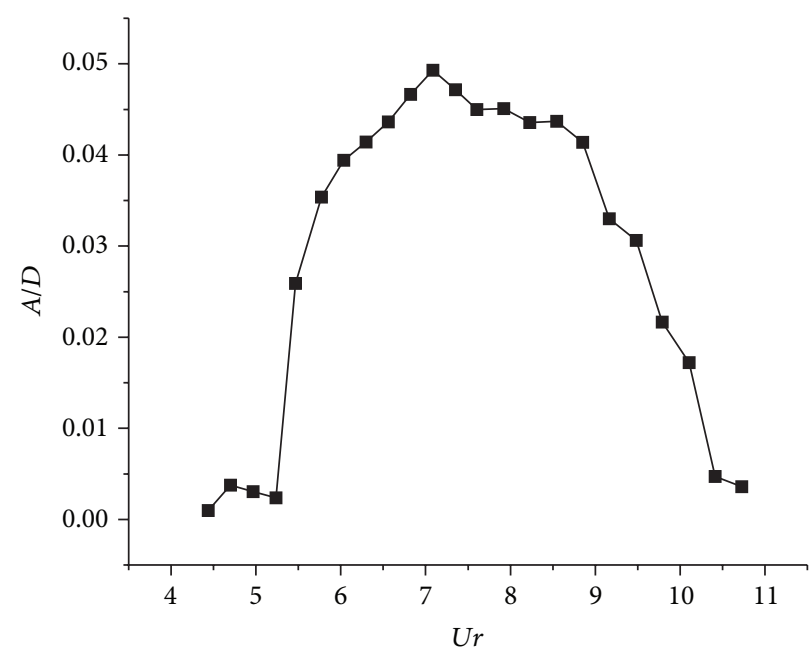

FIGURE 6: Amplitude of the bare cylinder versus the reduced wind speed.

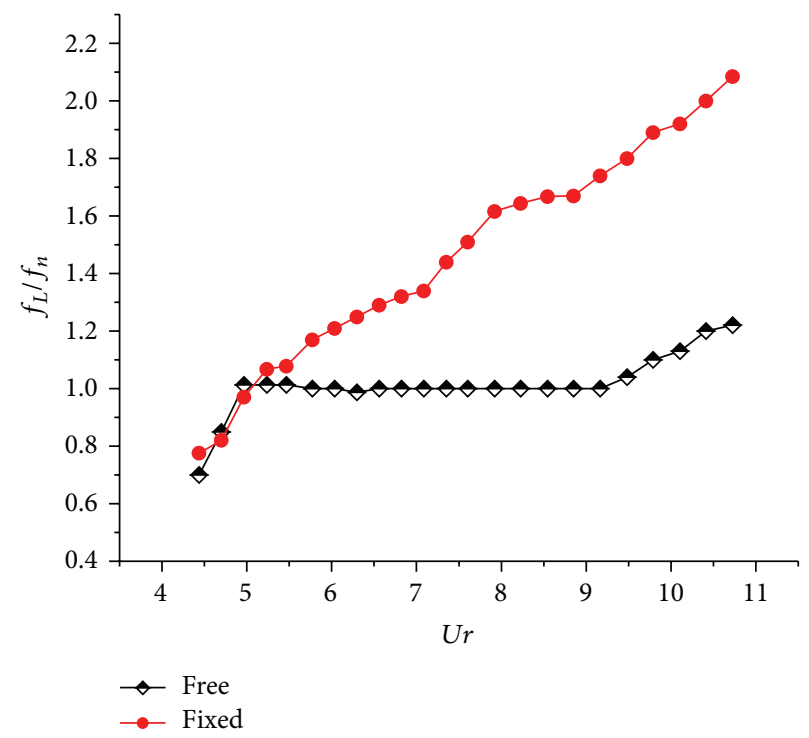

FIGURE 7: Variation of the frequency ratios versus the reduced wind speed.

wind velocity region from 5.0 to 9.2. For this region in the test system, the circular cylinder motion controls the vortex shedding frequency. Therefore, according to Figures 7 and 8, the synchronization region is from 5.0 to 9.2.

4.1. Displacement Amplitude. The displacement amplitudes of the circular cylinder with and without vortex generators are shown in Figure 8. The bare cylinder case was denoted by "BCC" throughout this study.

The VGs control has the positive effects on shortening the lock-in region and reducing the displacement amplitude of the circular cylinder. The results (in Figure 8) show that the control effect is excellent when $\theta$ is $70^{\circ}$. For $\theta=70^{\circ}$, a significant displacement amplitude reduction is achieved from $U r=5$ to $U r=10$. On the other side, for $\theta=90^{\circ}$ or $\theta=$ $105^{\circ}$, the VGs are less effective on reducing the displacement amplitude than that of $\theta=45^{\circ}$ or $\theta=70^{\circ}$. For $\theta=45^{\circ}$, there is early synchronization as that found for the circular cylinder subjected to VIV.

4.2. Surface Pressure Distribution. The mean surface pressure distribution on the circular cylinder is shown in Figure 9. By analysing the change of the surface pressure distributions, some conclusions can be drawn. First, one can observe how $C_{p, \min }$ is reduced to a value close to -2.5 for $\theta=70^{\circ}$ and is reduced to -2 for $\theta=45^{\circ}$. Second, the separation point moves towards the higher angles. Vortex generators make the boundary layer profile fuller and hence more 


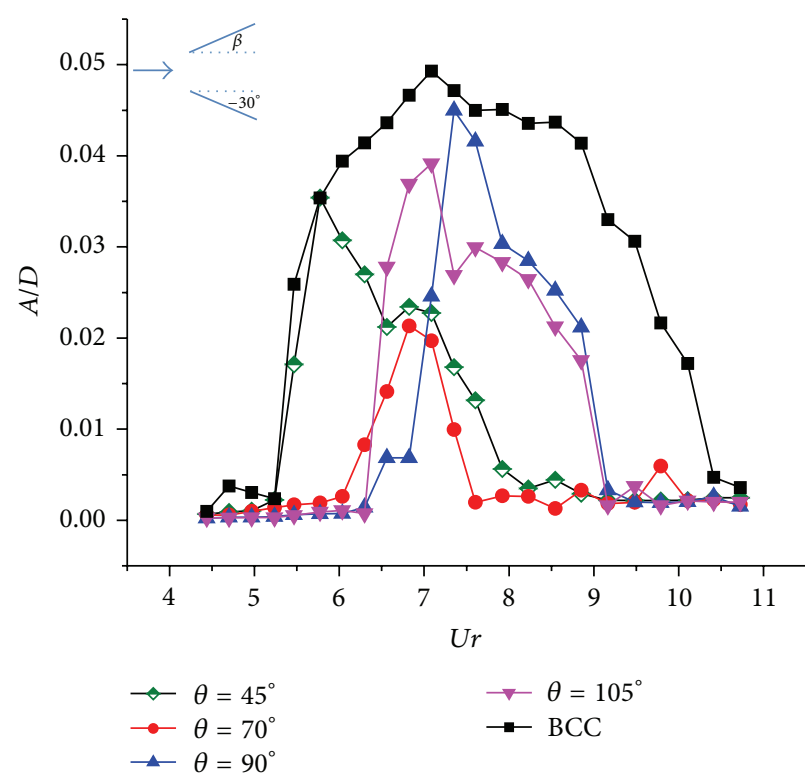

(a) $\beta=-30^{\circ}$

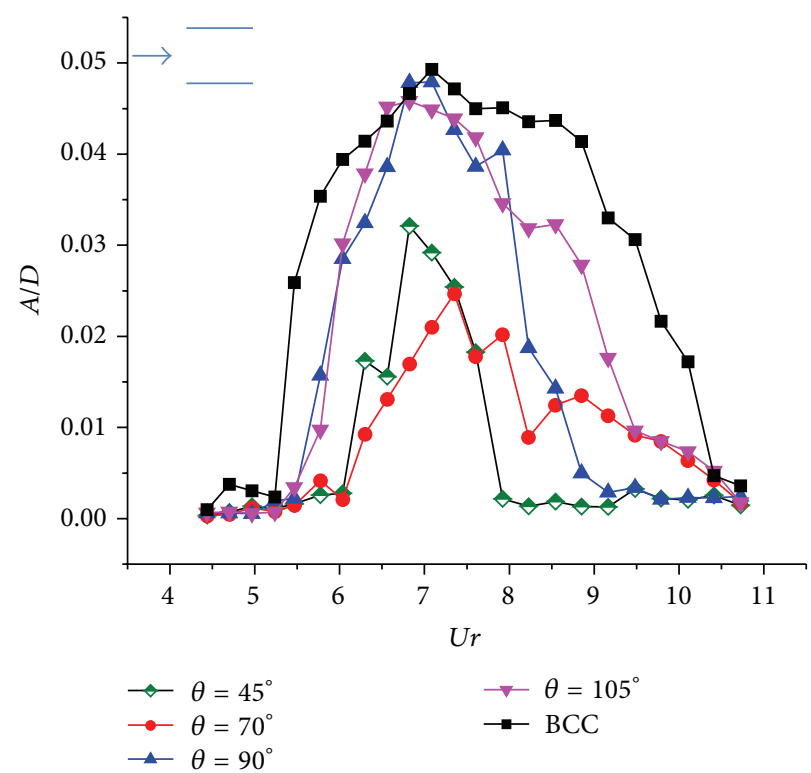

(b) $\beta=0^{\circ}$

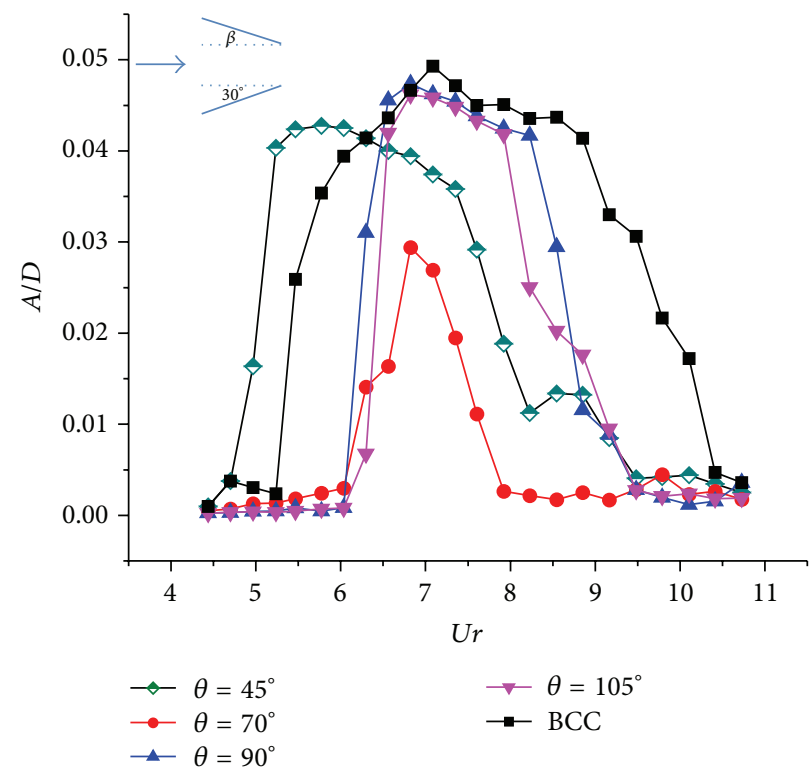

(c) $\beta=30^{\circ}$

Figure 8: Displacement amplitude.

resistant to separation. Third, the surface pressure distribution for $\theta=90^{\circ}$ is similar to that of the bare circular cylinder.

The fluctuating pressure coefficients $\left(C_{p}^{\prime}\right)$ distribution on the circular cylinder is plotted in Figure 10.

The fluctuating pressure distribution of the bare circular cylinder is roughly symmetrical. Every fluctuating pressure coefficient curve has two peaks. For the bare cylinder, the two peak points of the fluctuating pressure are $\alpha_{p 1}=72^{\circ}$ and $\alpha_{p 2}=288^{\circ}$. For $\theta=45^{\circ}$ and $\theta=70^{\circ}$, the maximum fluctuating pressure moves towards higher angles $\left(\alpha=108^{\circ}\right)$ and then rapidly decreases to approximately 0.05 . For $\theta=90^{\circ}$, the curve is almost the same as the bare cylinder case. For $\theta=45^{\circ}$, the fluctuating pressure increases to approximately 0.35 .

4.3. Correlation Analysis. Assuming that $\zeta$ and $\eta$ are two variables, the correlation coefficient $\left(r_{\zeta_{\eta}}\right)$ is

$$
r_{\zeta \eta}=\frac{\sum_{i=1}^{n}\left(\zeta_{i}-\bar{\zeta}\right)\left(\eta_{i}-\bar{\eta}\right)}{\sqrt{\sum_{i=1}^{n}\left(\zeta_{i}-\bar{\zeta}\right)^{2}} \sqrt{\sum_{i=1}^{n}\left(\eta_{i}-\bar{\eta}\right)^{2}}}
$$




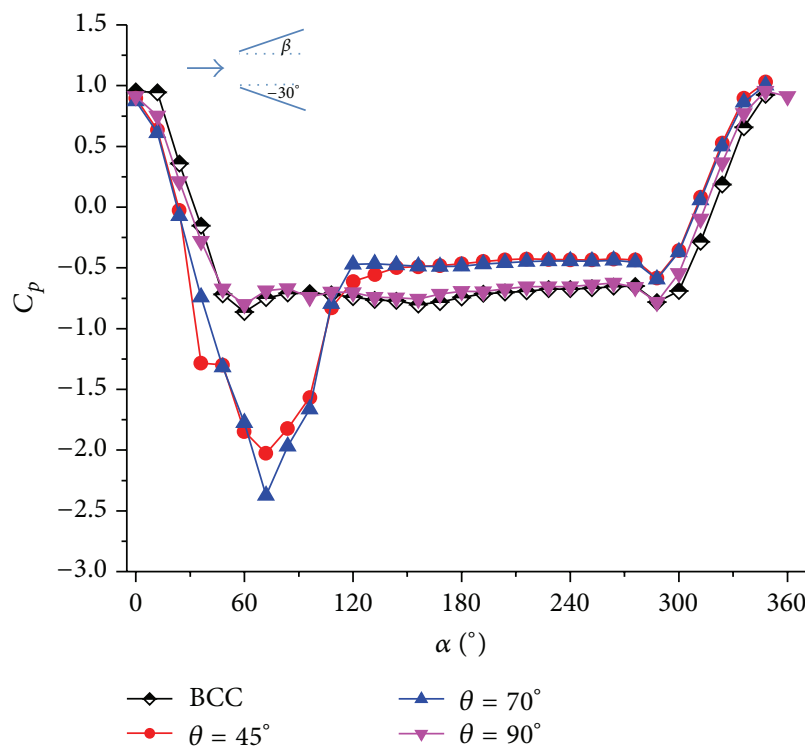

(a) $\beta=-30^{\circ}$

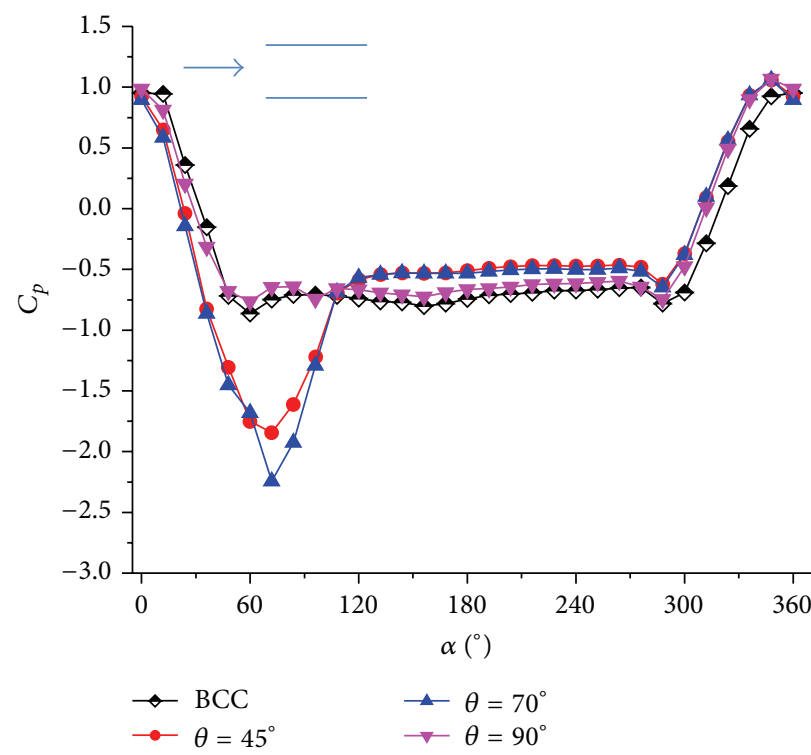

(b) $\beta=0^{\circ}$

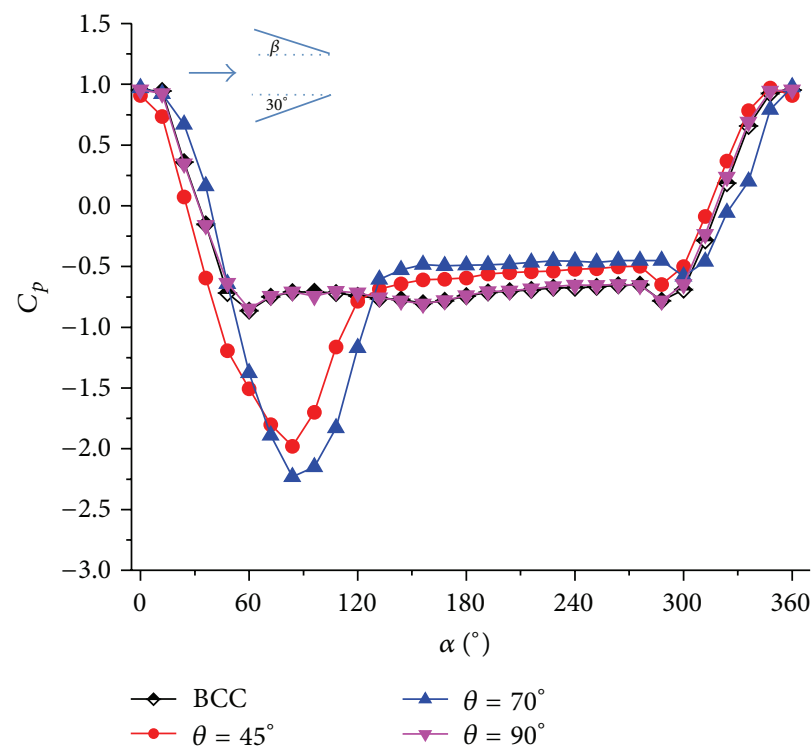

(c) $\beta=30^{\circ}$

Figure 9: Distribution of the mean pressure coefficients $(U r=7)$.

where $r$ is the correlation coefficient, $\bar{\zeta}$ is the mean of all $\zeta_{i}$-data, $\bar{\eta}$ is the mean of all $\eta_{i}$-data, and $n$ is the sampling length.

Correlation analysis can reveal the implicit periodicity of signals and detect the degree of correlation between two variables. The aerodynamic lift forces $\left(F_{y}\right)$ are obtained by integrating the surface pressure around the circular cylinder. The spanwise correlation coefficients between the aerodynamic lift forces on the middle section of the circular cylinder and the other three sections are shown in Figure 11.

For $\theta=45^{\circ}$ or $70^{\circ}$, the spanwise correlation coefficients of the aerodynamic lift forces are less than those of a bare circular cylinder. The VGs produce strong streamwise vortices to generate a disturbance in the spanwise direction. For $\theta=90^{\circ}$, however, the spanwise correlation coefficients are nearly the same as those without control.

In Figures 9-11, the VGs can influence the boundary layer flow even if they are far from the separation line $\left(\theta=45^{\circ}\right)$. When the VGs are set after the separation line $\left(\theta=90^{\circ}\right)$, however, the control effect is not significant.

The correlation coefficients between the two peak points of the fluctuating pressure for the bare cylinder $\left(\alpha_{p 1}=72^{\circ}\right.$ and $\alpha_{p 2}=288^{\circ}$ ) are shown in Figure 12. For the bare cylinder, there is a significant negative correlation coefficient between 


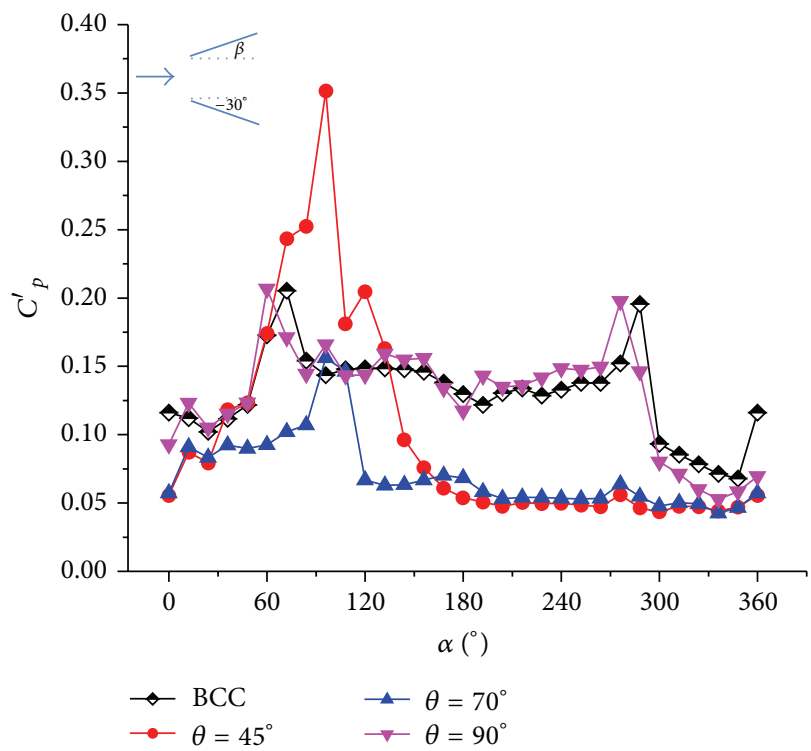

(a) $\beta=-30^{\circ}$

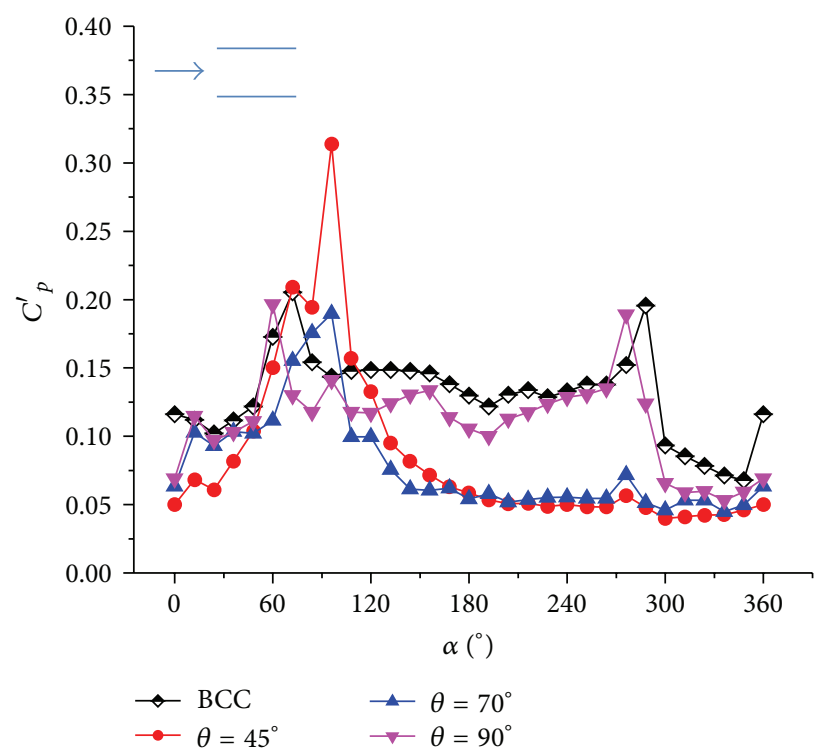

(b) $\beta=0^{\circ}$

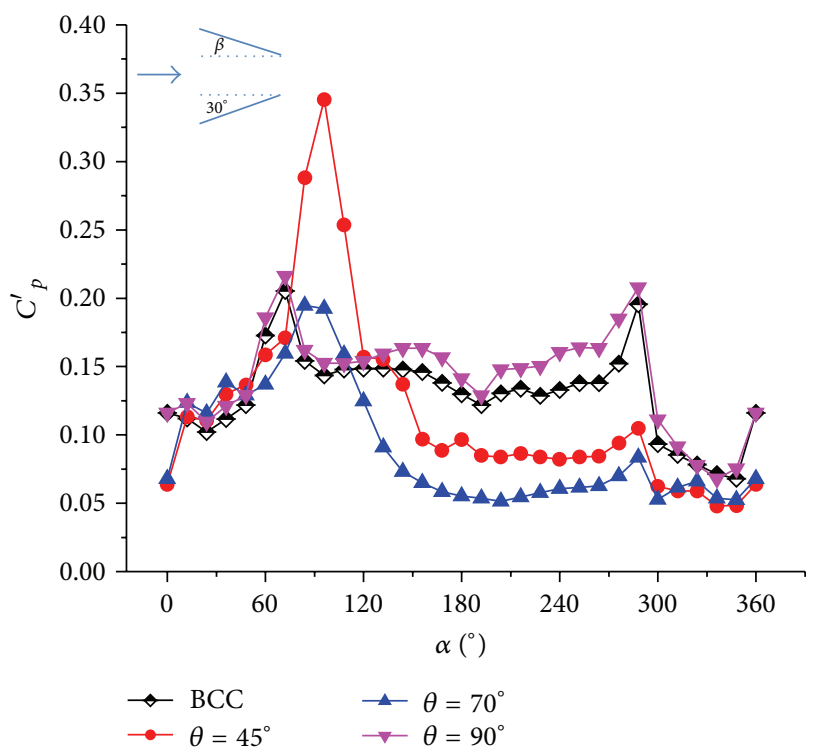

(c) $\beta=30^{\circ}$

FIGURE 10: Distribution of the fluctuating pressure coefficients $(U r=7)$.

the two peak points, indicating that there are two sets of alternating vortices on two sides. For $\theta=45^{\circ}$ or $\theta=70^{\circ}$, the correlation coefficients of the two peak points are closer to zero. This suggests that communication between the two shear layers is inhibited. For $\theta=90^{\circ}$, the negative coefficients are larger than that of $\theta=45^{\circ}$ and $\theta=70^{\circ}$.

\section{Conclusion}

Based on the wind tunnel experiment, a vibration control method using the vortex generator was studied herein. The vortex-induced vibration of the circular cylinder with and without vortex generators is quantified in terms of the displacement amplitude, pressure distributions, and correlation coefficients. The main results show the following:

(1) The vortex generators effectively suppress vortexinduced vibration. They shorten the lock-in region and reduce the amplitude of vortex-induced vibration. The vortex generators have the best result for $\theta=70^{\circ}$, which significantly reduces the amplitude. For $\theta=45^{\circ}$, there is early synchronization 


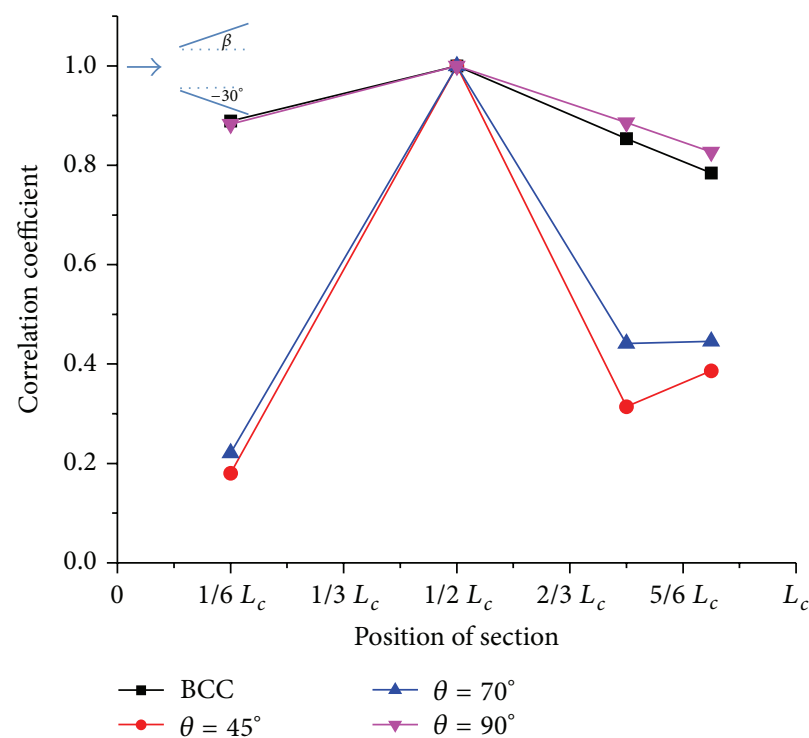

(a) $\beta=-30^{\circ}$

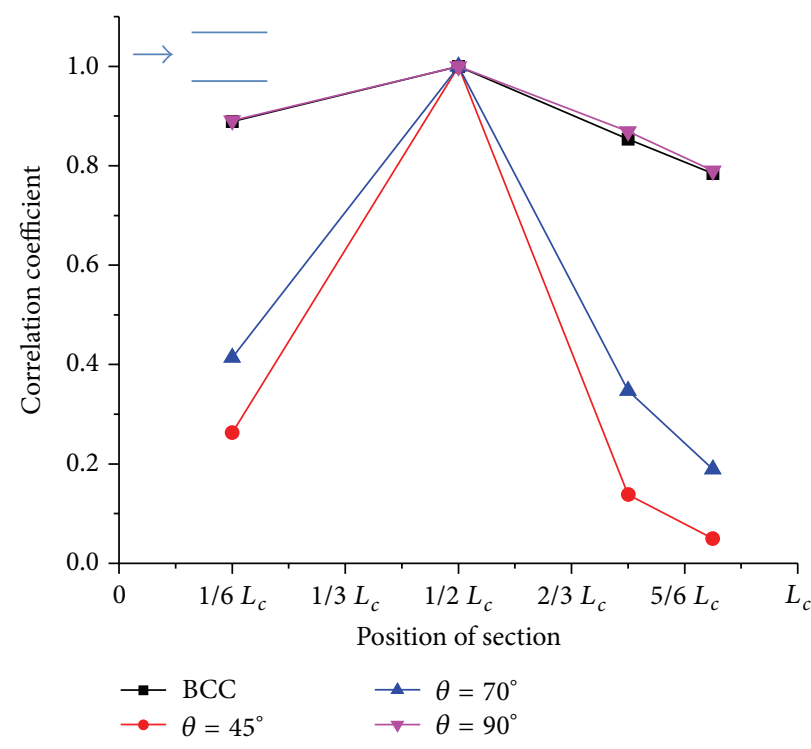

(b) $\beta=0^{\circ}$

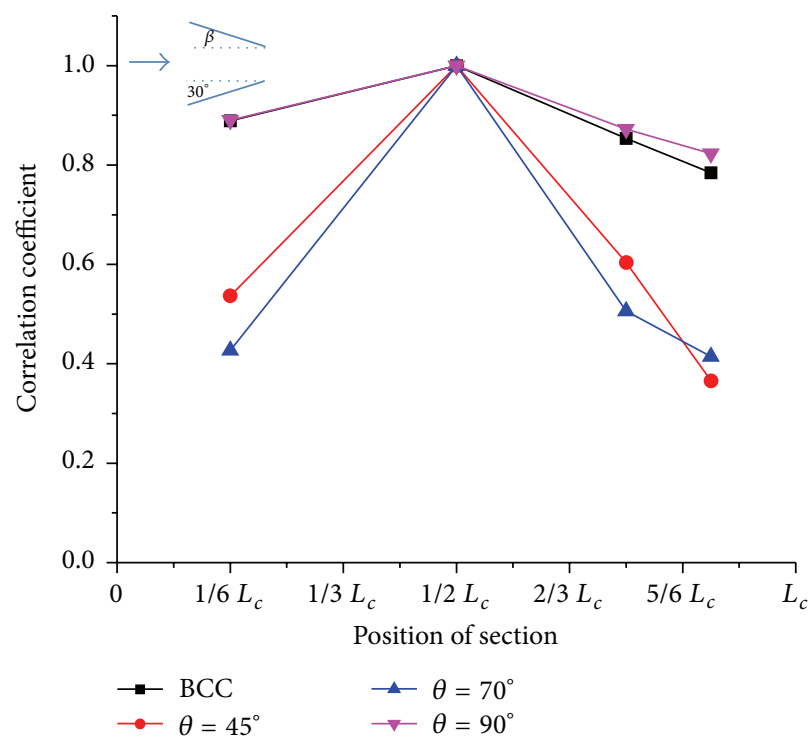

(c) $\beta=30^{\circ}$

FIGURE 11: Correlation coefficients of lift $(U r=7)$.

for a circular cylinder subjected to vortex-induced vibration.

(2) The vortex generators make the boundary layer profile fuller and hence more resistant to separation. They can influence the boundary layer flow even if they are far from the separation line.

(3) Correlation analysis shows that the vortex generators can inhibit communication between the two shear layers, and the vortex generators had a stronger effect on the spanwise correlation coefficients. The spanwise correlation coefficients of the cylinder with vortex generators are less than those of the bare circular cylinder.

We believe that the present study offers some information to understand the physics of the vortex-induced vibration of cylinders with and without vortex generators. Future test should focus on the enhanced physical understanding and continued application of vortex generators to real systems.

\section{Competing Interests}

The authors declare that there is no conflict of interests regarding the publication of this paper. 


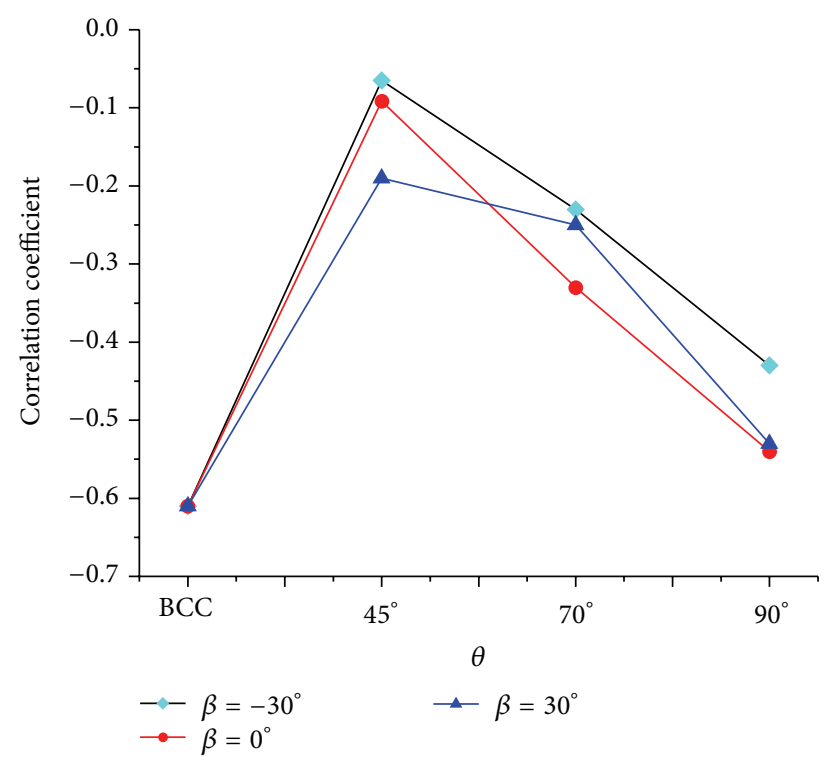

FIGURE 12: Correlation coefficients of the two peak points $(U r=7)$.

\section{Acknowledgments}

The authors extend their deepest gratitude to Ms. Cho Mya Darli for her comments on this paper. This research was funded by the National Basic Research Program of China (973 Program, 2011CB013705).

\section{References}

[1] W.-L. Chen, H. Li, J.-P. Ou, and F.-C. Li, "Numerical simulation of vortex-induced vibrations of inclined cables under different wind profiles," Journal of Bridge Engineering, vol. 18, no. 1, pp. 42-53, 2013.

[2] F. C. L. Borges, N. Roitman, C. Magluta, D. A. Castello, and R. Franciss, "A concept to reduce vibrations in steel catenary risers by the use of viscoelastic materials," Ocean Engineering, vol. 77, no. 2, pp. 1-11, 2014.

[3] H. L. Dai, A. Abdelkefi, L. Wang, and W. B. Liu, “Time-delay feedback controller for amplitude reduction in vortex-induced vibrations," Nonlinear Dynamics, vol. 80, no. 1-2, pp. 59-70, 2015.

[4] G. R. Franzini, A. L. C. Fujarra, J. R. Meneghini, I. Korkischko, and R. Franciss, "Experimental investigation of vortex-induced vibration on rigid, smooth and inclined cylinders," Journal of Fluids and Structures, vol. 25, no. 4, pp. 742-750, 2009.

[5] F. Landolsi, S. Choura, and A. H. Nayfeh, "Control of 2D flexible structures by confinement of vibrations and regulation of their energy flow," Shock and Vibration, vol. 16, no. 2, pp. 213-228, 2009.

[6] J. Kim and H. Choi, "Distributed forcing of flow over a circular cylinder," Physics of Fluids, vol. 17, no. 3, Article ID 33103, 2005.

[7] K. Muralidharan, S. Muddada, and B. S. V. Patnaik, "Numerical simulation of vortex induced vibrations and its control by suction and blowing," Applied Mathematical Modelling, vol. 37, no. 1-2, pp. 284-307, 2013.

[8] R. P. Bigger, H. Higuchi, and J. W. Hall, "Open-loop control of disk wakes," AIAA Journal, vol. 47, no. 5, pp. 1186-1194, 2009.

[9] V. J. Modi, "Moving surface boundary-layer control: a review," Journal of Fluids and Structures, vol. 11, no. 6, pp. 627-663, 1997.
[10] L. A. R. Quadrante and Y. Nishi, "Amplification/suppression of flow-induced motions of an elastically mounted circular cylinder by attaching tripping wires," Journal of Fluids and Structures, vol. 48, pp. 93-102, 2014.

[11] T. Adachi, "Effects of surface roughness on the universal Strouhal number over the wide Reynolds number range," Journal of Wind Engineering and Industrial Aerodynamics, vol. 69-71, pp. 399-412, 1997.

[12] W.-L. Chen, D.-L. Gao, W.-Y. Yuan, H. Li, and H. Hu, "Passive jet control of flow around a circular cylinder," Experiments in Fluids, vol. 56, article 201, 2015.

[13] V. Oruç, "Passive control of flow structures around a circular cylinder by using screen," Journal of Fluids and Structures, vol. 33, pp. 229-242, 2012.

[14] Y. Bao and J. Tao, "The passive control of wake flow behind a circular cylinder by parallel dual plates," Journal of Fluids and Structures, vol. 37, pp. 201-219, 2013.

[15] U. O. Ünal and Ö. Gören, "Effect of vortex generators on the flow around a circular cylinder: computational investigation with two-equation turbulence models," Engineering Applications of Computational Fluid Mechanics, vol. 5, no. 1, pp. 99-116, 2011.

[16] U. O. Ünal and M. Atlar, "An experimental investigation into the effect of vortex generators on the near-wake flow of a circular cylinder," Experiments in Fluids, vol. 48, no. 6, pp. 1059-1079, 2010.

[17] M. L. Shur, M. K. Strelets, A. K. Travin, and P. R. Spalart, "Evaluation of vortex generators for separation control in a transcritical cylinder flow," AIAA Journal, vol. 53, no. 10, pp. 2967-2977, 2015.

[18] G. Godard and M. Stanislas, "Control of a decelerating boundary layer. Part 1: optimization of passive vortex generators," Aerospace Science \& Technology, vol. 10, no. 3, pp. 181-191, 2006.

[19] H. F. Wang, Y. Zhou, and J. Mi, "Effects of aspect ratio on the drag of a wall-mounted finite-length cylinder in subcritical and critical regimes," Experiments in Fluids, vol. 53, no. 2, pp. 423436, 2012.

[20] F. Gu, J. S. Wang, X. Q. Qiao, and Z. Huang, "Pressure distribution, fluctuating forces and vortex shedding behavior of circular cylinder with rotatable splitter plates," Journal of Fluids and Structures, vol. 28, pp. 263-278, 2012.

[21] B. Çuhadaroğlu, Y. E. Akansu, and A. Ö. Turhal, "An experimental study on the effects of uniform injection through one perforated surface of a square cylinder on some aerodynamic parameters," Experimental Thermal \& Fluid Science, vol. 31, no. 8, pp. 909-915, 2007.

[22] W. Kessel, "European and international standards for statements of uncertainty," Engineering Science and Education Journal, vol. 7, no. 5, pp. 201-207, 1998. 


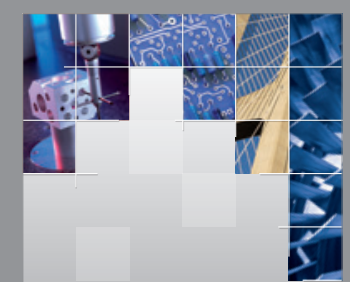

\section{Enfincering}
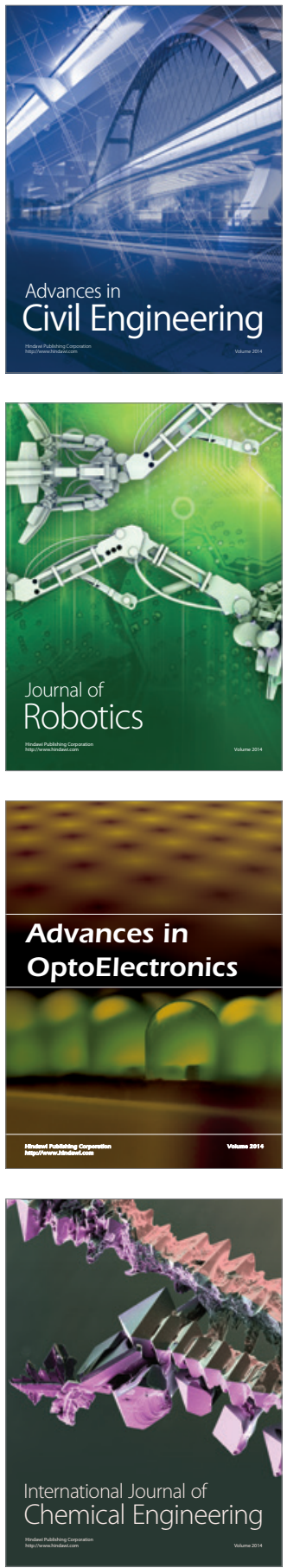

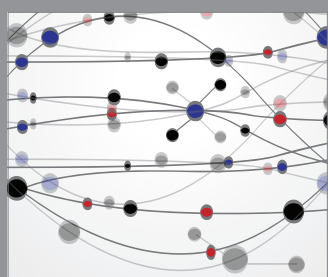

The Scientific World Journal

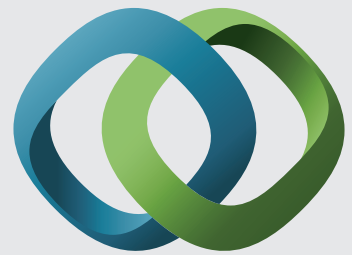

\section{Hindawi}

Submit your manuscripts at

http://www.hindawi.com
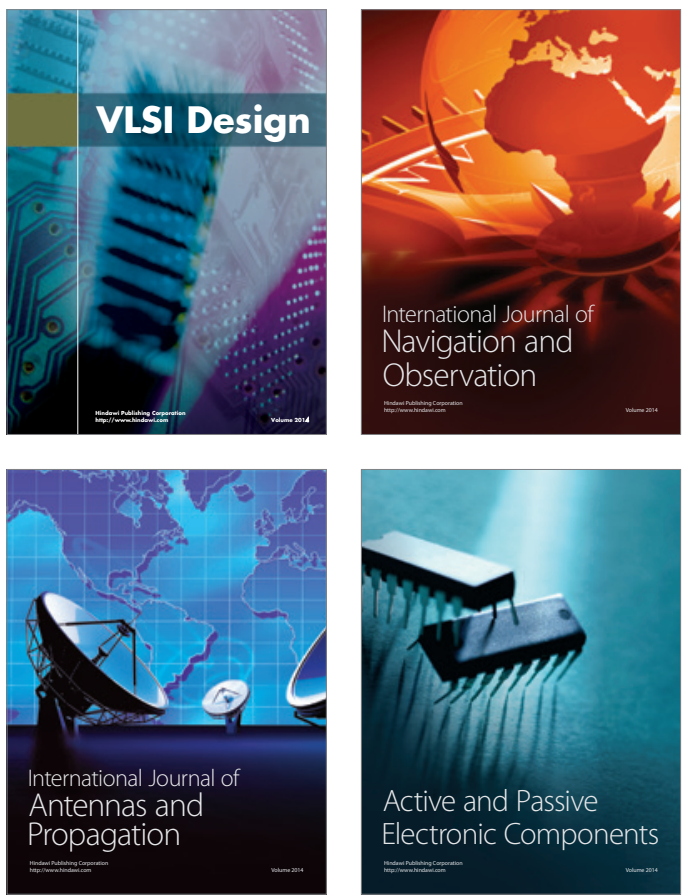
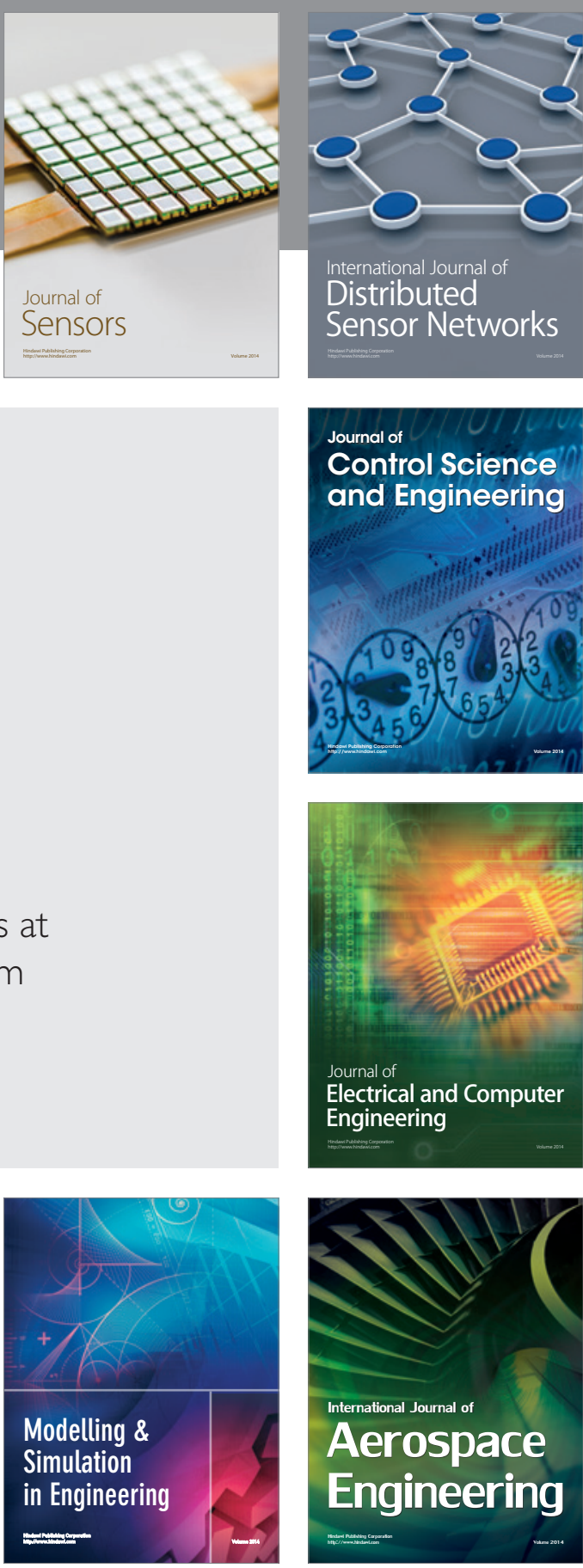

International Journal of

Distributed

Sensor Networks

Journal of

Control Science

and Engineering
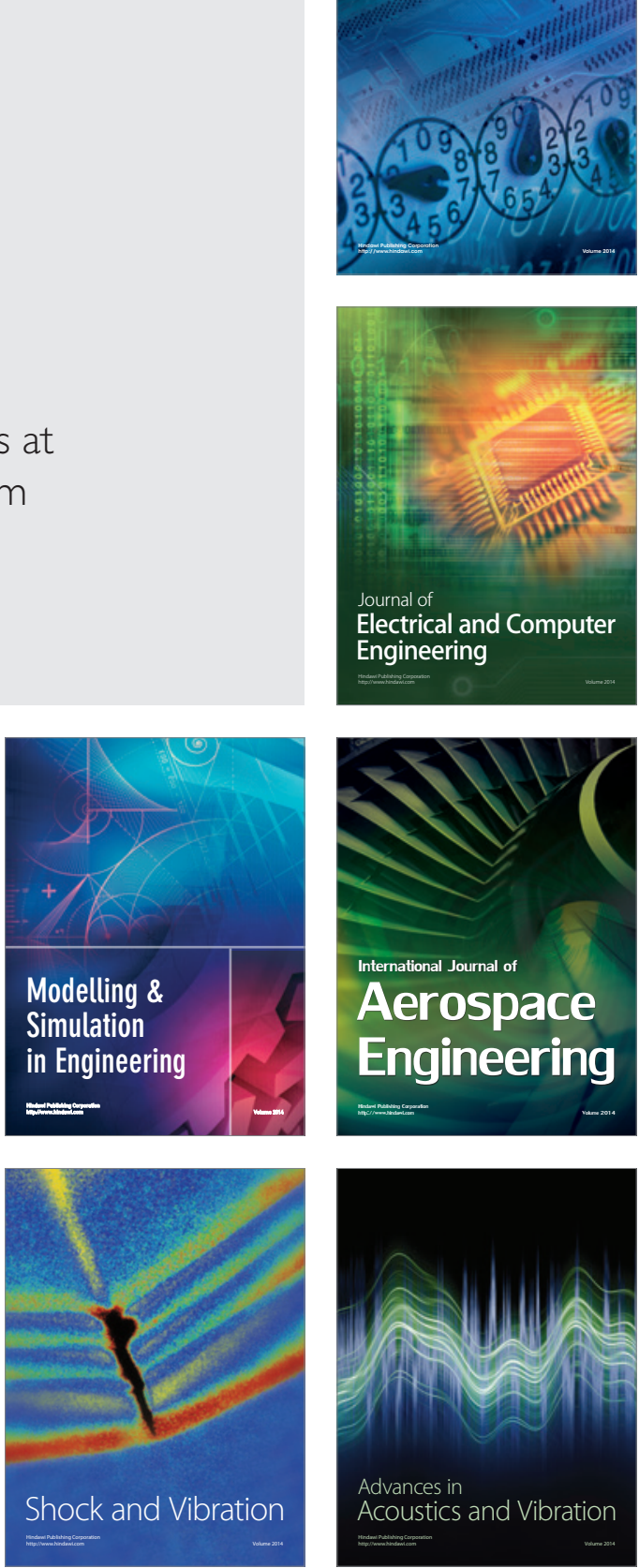